\title{
DESIGN: CONCEITOS E PROTEÇÃO JURÍDICA
}

\author{
Marina Veloso Mourão ${ }^{1}$ \\ Camila Soares Gonçalves ${ }^{2}$
}

\section{RESUMO}

A valorização de produto ou serviço customizado está cada dia mais presente na vida da população, que busca uma experiência ou um objeto que seja diferente, agradável e emocional. O presente estudo propõe analisar, com fundamento no método dedutivo, o descompasso entre o conceito jurídico de design e o conceito contemporâneo de design, considerando a legislação brasileira, tendo como marcos teóricos as leis $n^{\circ}$ 9.279/96 e $n^{\circ}$ 9.610/98 e o artigo Design Thinking e Direito escrito pelo Prof. Dr. Frederico de Andrade Gabrich.

Palavras-chave: Design. Design thinking. Propriedade intelectual. Direitos autorais. Desenho industrial.

\section{DESIGN: CONCEPTS AND LEGAL PROTECTION}

\begin{abstract}
The valorization of customized product or service is more and more present in the life of the population, who seeks an experience or an object that is different, pleasant and emotional. The present study proposes to analyze the mismatch between the legal concept of design and the contemporary concept of design, considering the Brazilian legislation, having as theoretical framework the laws 9.279 / 96 and 9.610 / 98 and the article Design Thinking and Law written by Prof. Dr. Frederico de Andrade Gabrich.
\end{abstract}

Keywords: Design. Design thinking. Intellectual property. Copyrights. Design patent.

\section{INTRODUÇÃO}

A atividade de design produz criações intelectuais que resultam da inteligência, criatividade e capacidade inventiva humanas. Vivemos em uma época na qual o modelo de produção em larga escala domina o mundo da indústria.

As empresas oferecem no mercado quase os mesmos produtos e serviços, por preços muito parecidos e cada vez menores, o que leva ao movimento de estreitamento das margens

\footnotetext{
${ }^{1}$ Mestranda em Direito Privado pela Universidade FUMEC. Mestre em Direito do Design pela Université Lumière Lyon2. Graduada em Direito pela UFMG. E-mail: marinavmourao@gmail.com Lattes: http://lattes.cnpq.br/1641460734552189

${ }^{2}$ Mestranda em Direito Privado pela Universidade FUMEC. Graduada em Direito pela Rede Doctum. Professora do Curso Pro Labore e pós-graduação da ESA OAB/MG e UNIFEMM. E-mail: camilasoaresg@gmail.com Lattes: http://lattes.cnpq.br/1247516173425206
} 
de lucros e padronização dos modelos de negócios. No século XXI as pessoas querem, em regra, produtos e serviços mais customizados, bonitos, funcionais e emocionais. No entanto, as empresas somente conseguem oferecer isso com pesquisa, inovação e design de produtos, serviços, de interação e de ideias. Com o design busca-se criar identidade, a exclusividade e a personalização.

Todavia, o conceito jurídico clássico do design está atrelado à proteção da forma plástica do objeto, de uma combinação puramente estética, fútil e sem caráter útil. Definir design não é tarefa fácil, esse termo originário do inglês foi progressivamente vinculado ao desenvolvimento da industrialização e mecanização, inovação, quase sempre para determinar qualidades formais de objetos.

Assim, com fundamento no método dedutivo e tendo como marco teórico a Lei de Direitos Autorais e a parte reservada aos desenhos industriais da Lei de Propriedade Industrial, pretende-se discutir o descompasso entre o conceito jurídico e o conceito contemporâneo de design, a necessidade do desenvolvimento de estudos que reconheçam juridicamente a ampliação do conceito de design, bem como a possibilidade de aplicação cumulativa de instrumentos jurídicos de proteção da propriedade intelectual de produtos e serviços.

\section{DESIGN THINKING}

O design thinking é um novo modelo mental de pensar e de abordar a solução das contradições e dos problemas reais das pessoas oferecendo um produto ou serviço desejável, tecnológico e economicamente viável. O design thinking não se trata de estética, mas sim de aplicar os princípios do design na forma como as pessoas trabalham. Essa abordagem é o resultado da crescente complexidade das novas tecnologias e dos negócios contemporâneos.

Através dele, alia-se a necessidade humana aos recursos técnicos disponíveis, ao desejável e à viabilidade econômica para chegar a soluções voltadas para a superação de contradições empresariais e pessoais. Essa metodologia concebida por Tim Brown no início dos anos 1990, que busca uma 'terceira via' alternativa, está integrada ao conhecimento e a colaboração multidisciplinar com a finalidade de permitir o desenvolvimento de novas ideias voltadas para a estruturação de objetivos e/ou solução de reais problemas.

Diversas empresas vêm usando a metodologia do Design Thinking para a solução de seus problemas e contradições, na busca por novos produtos e serviços, úteis e 
visualmente agradáveis. Mais que um instrumento para a solução de problemas, o Design Thinking é uma metodologia de formulação de ideias, de criação e/ou do aprimoramento de produtos, de serviços e/ou de processos administrativos, baseada na observação, na empatia, na colaboração entre clientes e desenvolvedores, bem como na experimentação de protótipos (GABRICH, 2012, p. 313).

A cultura do design tende a ser mais tolerante com eventuais falhas, pois reconhece que raramente as coisas acontecem como gostaríamos logo na primeira tentativa, pois os equívocos fazem parte do desenvolvimento das ideias. As empresas aproveitam o fracasso como aprendizado, incluindo-o no custo relacionado à inovação. Assim, segundo o designer de automóveis Ralph Gilles:

Tudo precisa ser arte. Não é só projetar para a Chrysler, mas para outros designers. Então precisamos nos superar. O carro precisa ficar bonito, ficar bem na estrada e representar bem não apenas a marca, mas ser uma criação atraente de Detroit. [...] Toda marca, sem exceção, já fez um produto ruim que manchou um pouco a marca. Mas sou otimista. Acredito em redenção pelo design. É possível criar um produto que revitalize a marca, por meio da engenharia e do design. [...] Tudo precisa ser feito com amor, seja um limpador de para-brisas ou uma proteção de motor. $\mathrm{O}$ observador vai reconhecer isso. 'Nossa, alguém deu atenção a isso!'. É isso que leva a um bom design, e a uma boa arte (ABSTRACT: THE ART OF DESIGN, 2017, ep. $5)$.

Uma cultura centrada no design é caracterizada por um conjunto de concepções que pode auxiliar qualquer um a ter ideias que servem para a vida. O objetivo do design, é transmitir uma sensação com foco nas experiências dos usuários, principalmente nas emocionais. Sobre o tema, Jon Kolko (2015) estabelece que:

Para construir empatia com os clientes, organizações centradas no design precisam capacitar os funcionários a observar comportamentos e tirar conclusões sobre o que as pessoas querem e precisam. É muito difícil expressar esses dados em linguagem quantitativa. Por isso, empresas que adotam o design devem usar os códigos emocionais (palavras relacionadas com desejos, aspirações, compromisso e experiências) para descrever produtos e usuários. E os membros da equipe precisam discutir tanto a ressonância sentimental de uma proposta de valor quanto a utilidade e os requisitos do produto (KOLKO, 2015, on-line).

O design thinking, inicialmente utilizado para produzir objetos, tem sido cada vez mais aplicado a questões intrincadas, mas tangíveis: por exemplo, em como um cliente experimenta um serviço. Independentemente do contexto, nessa abordagem o profissional tende a usar modelos físicos, também conhecidos como artefatos de design, para explorar, definir parâmetros e se comunicar. Esses modelos (principalmente diagramas e desenhos) podem complementar e, em alguns casos, substituir planilhas, especificações e outros documentos que costumam compor o ambiente organizacional tradicional. Também favorecem a fluidez na investigação de temas complexos e permitem pensar de forma criativa na hora de abordar problemas complicados (KOLKO, 2015, on-line).

Nesse sentido, para Tim Brown:

El design thinking [...] en términos sencillos, es una disciplina que usa la sensibilidad y los métodos del diseñador para hacer coincidir lasa necesidades de las 
personas con lo que es tecnológicamente factible y con lo que una estrategia viable de negocios puede convertir en valor para el cliente y en una oportunidad de mercado (BROWN, 2008, p. 3).

Para o professor Frederico Gabrich,

Está em curso, claramente, uma transição do capitalismo consumista tradicional, em que prevalece a preferência pelo preço e depois pelo produto, para uma "era da experiência", em que o consumidor exige atenção, emoção, atendimento customizado e a possibilidade de participar e colaborar - muitas vezes gratuitamente - com seus fornecedores de produtos e de serviços. Em virtude dessa realidade, é preciso observar as pessoas em seu dia a dia, inferir seus desejos e reais necessidades, para garantir o desenvolvimento de produtos e de serviços que facilitem de fato suas vidas, mas que também sejam visualmente agradáveis e bonitos (GABRICH, 2012, p. 312).

O Design Thinking pressupõe que, na atualidade, não existem verdades absolutas, tampouco donos exclusivos do saber. Em um ambiente em que as informações são excessivas, onipresentes e gratuitas, o processo de cocriação de ideias é natural e flui de maneira às vezes caótica e outras vezes sistemática dentro das equipes criativas, independentemente de formação acadêmica ou de hierarquia funcional (GABRICH, 2012, p. 324-325).

O design thinking tem potencial de solução para quase todos problemas. Segundo Kolko, muitos designers, aproveitam essa influência estratégica e reforçam essa impressão. O design, obviamente, não resolve tudo, mas pode ajudar pessoas e organizações a atravessar situações complexas pois é uma excelente estratégia para a inovação, além de funcionar bem para auxiliar a estimar dados.

Em organizações centradas no design é comum observar moldes que representam novos conceitos, produtos e serviços espalhados pelos ambientes. O foco visual e organizacional no design pode contribuir para a humanização da tecnologia e para o desenvolvimento de produtos e serviços que ressoem emocionalmente e que atendam mais aos desejos, propósitos, vontades e necessidades de parte significativa dos consumidores contemporâneos.

\section{DESIGN}

A atividade de criação de design engloba tanto a técnica quanto a estética, e o autor é o responsável pela inserção de uma gama enorme de produtos e imagens no mercado, para isso ele deve estar atendo à legislação que diz respeito às criações intelectuais.

Um dos principais atributos do design é fazer com que as pessoas notem e se apaixonem pelas coisas, mas, cada vez mais, ele está longe de somente dar forma e beleza a algo, mas de transformar uma coisa existente em uma preferida. Seu objetivo passou a ser o de garantir que uma oferta de produto ou de serviço seja percebida pelas pessoas como algo de alto valor para as suas vidas pessoais ou 
profissionais (GABRICH, 2012, p. 318).

A utilização do termo muitas vezes confronta o leitor com diferentes pontos de vista e múltiplos conceitos, o que tente a causar mais confusão do que clareza. O design conceitua-se como "corporificação" de uma ideia, um projeto ou um plano, que com a ajuda dos meios correspondentes, permite a sua transmissão aos outros (LÖBACH, 2001) apud (PENIDO, 2016, p. 33).

Conforme Campos (2011) o início da utilização do termo design foi

no período após a Revolução Industrial, especificamente para configurar a divisão entre artesanato e indústria. Naquele momento os princípios Modernistas de "forma segue a função" traçaram a trajetória de desenvolvimento dos produtos, que continham a diretriz clara da necessidade de um projeto para reprodução industrial, e cuja função era sinônimo de utilidade (CAMPOS, 2011) apud (PENIDO, 2016, p. $11)$.

De acordo com os dicionários da língua portuguesa consultados, a palavra design acolhe os seguintes significados:

Design \dı'zajn\[ing.] s. m. DES. IND 1 a concepção de um produto (máquina, utensílio, mobiliário, embalagem, publicação etc.), esp. no que se refere à sua forma física e funcionalidade 2 p. met. o produto desta concepção 3 p. ext. (da acp. 1) m. q. DESENHO INDUSTRIAL 4 p. ext. m. q. DESENHO DE PRODUTO 5 p. ext. m. q. PROGRAMAÇÃO VISUAL 6 p. ext. m. q. DESENHO ('forma do ponto de vista estético e utilitário' e 'representação de objetos executada para fins científicos, técnicos, industriais, ornamentais’) $\square$ d. gráfico DES. IND GRÁF conjunto de técnicas e de concepções estéticas aplicadas à representação visual de uma ideia ou mensagem, criação de logotipos, ícones, sistemas de identidade visual, vinhetas para televisão, projeto gráfico de publicações impressas etc.; comunicação visual (HOUAISS; VILLAR, 2009, p. 654).

Design. [.də’zajn] [Ingl.] S. $\boldsymbol{m}$. 1. Concepção de um projeto ou modelo; planejamento. 2. O produto desse planejamento. 3. Restr. Desenho industrial. 4. Restr. Desenho-de-produto. 5. Restr. Programação visual (FERREIRA, 1999, p. 654).

O design é uma experiência visual, instantânea e plena. O trabalho do designer consiste em transformar algo existente em algo preferido, assim, ele garantirá que o produto e serviço ofertado seja percebido pelas pessoas como algo de valor para suas vidas.

O designer irá observar as necessidades e problemas, formulará ideias inovadoras, planejará, criará e recriará produtos e serviços, transmitirá ideias e conteúdos com a finalidade de atrair, emocionar e cativar seu cliente. Ele buscará sempre a melhor e mais eficiente relação entre forma e conteúdo, entre comunicação verbal e visual dos produtos e dos serviços. Mas, como os designers entendem o design?

\subsection{NA VISÃO DO DESIGNER}

Revista de Direito, Arte e Literatura | e-ISSN: 2525-9911 | Belém | v. 5 | n. 2 | p. 78 - 98 | Jul/Dez. 2019. 
O aclamado fotografo grego Platon (ABSTRACT: THE ART OF DESIGN, 2017, ep. 7), afirma que "o que importa é a história, a mensagem, o sentimento. A conexão. Como fazer isso? Como atingir as pessoas? Numa mistura de simplicidade gráfica e poder da alma. Isso é design!”.

Já a designer gráfica americana Paula Scher (ABSTRACT: THE ART OF DESIGN, 2017, ep. 6), sustenta que "o design existe além das telas, tem um impacto na vida real. Existe um aspecto emocional. O design precisa levar em conta o comportamento humano".

Nesse sentido, aduz a designer de interiores britânica Ilse Crawford:

\begin{abstract}
Alguns acham que design de interiores é sobre aparência. 'Deve ser divertido ficar comprando móveis', uma pessoa me disse uma vez. Mas não penso assim. Passamos $87 \%$ da nossa vida dentro de edifícios. O design deles tem um impacto em como nos sentimos e comportamos. Design não é apenas o aspecto visual, é um processo mental, uma habilidade. Acima de tudo, é uma ferramenta para acentuar nossa humanidade. É uma moldura para a vida. [...] Nossos projetos começam com uma estratégia. Priorizamos as pessoas e pensamos na experiência humano no início do processo de design. No processo, analisamos o local, o cliente, e criamos empatia, porque empatia é um dos alicerces do design. Depois desse processo de análise e empatia é que entra o processo imaginativo. [...] O interior foi, por muito tempo, visto como um aspecto mais bobo do design, e agora está começando a ser levado a sério. [...] Fazer sentir bem, além de ser bonito. [...] Usar o design para aprimorar. Incorporar emoção nesse sistema, para desenvolver produtos sustentáveis, mas que as pessoas adorassem. [...] Não queríamos só criar produtos, queríamos criar uma experiência. [...] O design tira proveito das restrições. [...] O bem-estar agora é uma filosofia que permeia muitos designers. [...] Quando priorizamos as necessidades humanas em um espaço o design pode causar um impacto profundo. Espero contribuir para a felicidade humana, para fazer um mundo melhor (ABSTRACT: THE ART OF DESIGN, 2017, ep. 8).
\end{abstract}

O discurso de Crawford é bem esclarecedor, demonstra que o consumidor busca do designer atenção, emoção, atendimento customizado e às vezes até a possibilidade de participar e colaborar.

Sobre o design colaborativo, Mathilde Berchon (2012, p. 186) explica que, o coletivo de designers americanos Nervous System ${ }^{3}$ se especializou na criação de design customizável de joias ou bijuterias, impressos em 3D. Os anéis, braceletes e colares produzidos por eles reproduzem formas orgânicas complexas que podem ser modificados diretamente pelo cliente graças a uma interface online.

A customização de um design é efetuada nas seguintes etapas: primeiro o designer cria o objeto inicial e suas variantes opcionais, que são apresentadas ao consumidor num ponto de venda ou via web. Em seguida, o consumidor escolhe dentre as opções disponíveis

\footnotetext{
${ }^{3}$ Nervous System - https://n-e-r-v-o-u-s.com/
} 
aquela que preferir, fazendo alterações no objeto. Por fim, este é produzido sob demanda enviado ao consumidor.

Outra empresa que trabalha de forma semelhante é a Sculpteo ${ }^{4}$, que lançou em 2012, um serviço online que permite customizar uma capa de telefone celular a partir de um modelo concebido por um designer, antes de recebe-la via postal. A partir de um aplicativo de celular ou de sites, basta selecionar a forma básica da capa e em seguida personalizar suas características físicas (adicionando textos, imagens ou ainda distorcer suas formas) e escolher seu material. Após, cada capa com visual único é impressa e enviada ao cliente.

\title{
3.2 DESIGN X ARTE
}

Seria o design sinônimo de arte? Para o designer de tênis da Nike, Tinker Hatfield:

Eu acho que existe arte envolvida no design. Mas não acho que seja arte. Na minha percepção, arte é a maior auto-expressão de um indivíduo criativo. Para mim como designer o maior objetivo não é a auto-expressão. Meu objetivo é solucionar um problema para outra pessoa e espero que fique ótimo para ela, e bonito. É assim que o design funciona para mim. [...] Um design básico é funcional. Mas um ótimo passa uma mensagem (ABSTRACT: THE ART OF DESIGN, 2017, ep. 1).

Segundo Eurico Valeriano Baptista (Coordenador do curso de Design Gráfico da UEMG/2008) apud (MARTINS, 2009, p. 52):

\begin{abstract}
a resposta mais simples à questão "o design é uma arte?" é "não". Para ele, o design não deve ser chamado de arte, considerando a forma como a história da arte moderna e contemporânea encaram o design: a partir do século XIX, o termo "arte" ganhou um sentido ideológico ligado a uma produção material individualista e transcendente, enquanto que o design defendia uma atividade funcional que atendesse à sociedade.
\end{abstract}

Dessa maneira, conclui-se que design e arte não são sinônimos, pois a arte é puramente formal, os elementos artísticos e as concepções artísticas são formais. Já o design é a forma associada à função, os objetos de design implicam a conjunção entre a forma e a função destes.

\subsection{NA VISÃO DOS JURISTAS}

E para os juristas, o que é o design? Conforme Martins (2009, p. 43) o design é o diferencial de um produto lançado num mercado abarrotado por um numero excessivo de produtos semelhantes, de mesma tecnologia, mesmo preço, mesmo desempenho e mesmas

\footnotetext{
${ }^{4}$ Sculpteo - https://www.sculpteo.com/en/
} 
características, que, ao confundir e dificultar o consumidor na percepção das diferenças faz com que este não consiga atribuir a elas o seu devido valor.

Como o design é uma criação intelectual (um bem intangível) que surge da criatividade e capacidade imaginativa do homem, para agregar valor às novas obras e aparatos, transformando um bem que não possuía economicidade em bem econômico, cabe ao seu autor impor os limites pelos quais esse novo produto venha a ser utilizado por terceiros (MARTINS, 2009, p. 47).

O professor Gabrich (2012, p. 319) explica que no campo exclusivamente jurídico, o termo design tem geralmente como única referência direta a sua relação com a propriedade intelectual e, mais especificamente, com o direito autoral de desenhos e de projetos arquitetônicos, bem como com a propriedade do desenho industrial. E ainda, afirma que

para o sistema brasileiro de proteção da propriedade industrial, o design de produto vale e merece proteção legal pela sua futilidade e não pela sua utilidade. Em outras palavras, a lei considera fundamentalmente o desenho industrial como arte aplicada à forma plástica ou ornamental de um produto, sem que esta aprimore ou acrescente qualquer nova funcionalidade ao objeto (GABRICH, 2012, p. 320).

Para Domingues (2008) apud Martins (2009, p. 24), a concepção mais básica do design associa-se sim a valores estéticos, mas é possível se entender o design também como um processo criativo, inovador e provedor de soluções para problemas, de importância fundamental, não apenas para a esfera produtiva, tecnológica e econômica, mas também cultural, ambiental e social.

No contexto de peças de vestuário, Karin Grau-Kuntz (2015), definiu a expressão design nos seguintes termos:

Se a expressão design reporta a uma composição nova ou original, isto é, a um desenho industrial, então a composição estético funcional que não satisfaça as condições da novidade ou da originalidade não deverá, sob uma perspectiva jurídica, ser indicada pelo emprego da expressão design (ou pela expressão desenho industrial). Mas mesmo as composições que não satisfaçam os requisitos da novidade ou da originalidade, portanto que não satisfaçam as condições que permitem serem denominadas como design (ou como desenho industrial), e consequentemente que não possam gozar de proteção por esta via, poderão ser protegidas pela propriedade intelectual (GRAU-KUNTZ, 2015, p. 114).

Ao conceituar design, Guimarães (2010) aponta que

o objeto artístico identifica-se com o resultado da ideia, e design tem a ver com projeto de produto. Estamos nos referindo ao design e à arte tridimensional. Entretanto, quando tratamos de objeto de design, não poderemos concluir que um produto industrial não é o resultado de uma ideia original (GUIMARÃES, 2010, p.76).

Nota-se que o design diz respeito a produtos, serviços e sistemas concebidos a partir de ferramentas, organizações e lógica introduzidos pela industrialização e não apenas quando 
produzidos por meio de processos em série. E que o designer foca nas experiências e nos sentimos para satisfazer o subconsciente de seu cliente. Com o design, busca-se a transmissão de uma sensação de bem-estar, empoderamento e certa alegria.

Nesse sentido, de acordo com Gabrich (2012):

Há, entretanto, um total descompasso entre o conceito jurídico geralmente aceito de design (forma plástica e ornamental de um objeto, de um produto ou de um projeto arquitetônico, considerado independentemente de sua utilidade) e o conceito contemporâneo de design (forma atraente e útil de um objeto e/ou de um serviço, usada para a transmissão de ideias, de conteúdo e/ou de conhecimento, e voltada para a facilitação da vida das pessoas) (GABRICH, 2012, p. 322).

Conclui-se, que a legislação ainda está muito vinculada ao caráter fútil e não ao caráter útil do desenho industrial. Para a lei, o desenho industrial é uma alteração introduzida no objeto que não amplia sua utilidade, mas apenas lhe atribui um aspecto diferente. E para o design, não há atividade inventiva, mas apenas a mudança da natureza estética do objeto.

\section{PROPRIEDADE INTELECTUAL}

Deve ser assinalado que a expressão "direitos de propriedade intelectual" pode designar os diferentes tipos de direitos subjetivos que os ordenamentos jurídicos modernos atribuem aos autores de criações espirituais, comerciais ou industriais.

Os direitos de propriedade intelectual existem de forma independente em relação ao suporte físico no qual possam ser incorporados, além de possuírem valor econômico para pessoas físicas ou jurídicas, bem como para o sistema econômico como um todo. Os bens intelectuais constituem ativos valiosos e estratégicos que permitem às empresas diferenciar seus produtos e serviços, obter vantagens competitivas que os bens físicos muitas vezes não são capazes de conferir. O bem intangível de uma empresa pode ser representado por tecnologias, ideias, design e valor estratégico criado pelo desenvolvimento de informação e pela criatividade, tais como novas tecnologias, marcas, patentes, segredos industriais e de negócios, serviços e softwares. Nesse sentido, de acordo com Lilla (2011):

A propriedade intelectual pode ser compreendida, em termos gerais, como o conjunto dos direitos relativos às obras literárias, artísticas, científicas, às invenções, desenhos e modelos industriais, às marcas, firmas comerciais e denominaçõoes comerciais, à proteção contra a concorrência desleal e todos os outros direitos inerentes à atividade intelectual nos domínios industrial, científico, literário e artístico. [...] Tradicionalmente, a propriedade intelectual é dividida em direitos de propriedade industrial (patentes, modelos de utilidade, desenhos industriais e marcas), e direitos autorais (direitos de autor, direitos conexos e a proteção dos programas de computador), muito embora existam atualmente outros tipos de diretos de propriedade intelectual que não necessariamente se enquadram na dicotomia 
direito industrial e autoral (LILLA, 2011, p. 124).

No tocante à proteção do design, no diagrama e legendas abaixo, Martins (2009) aduz que há cinco formas legais de protegê-lo: através dos direitos autorais; do registro de marca; do registro de desenho industrial; ou ainda por registros de patente de invenção ou registro de modelo de utilidade.

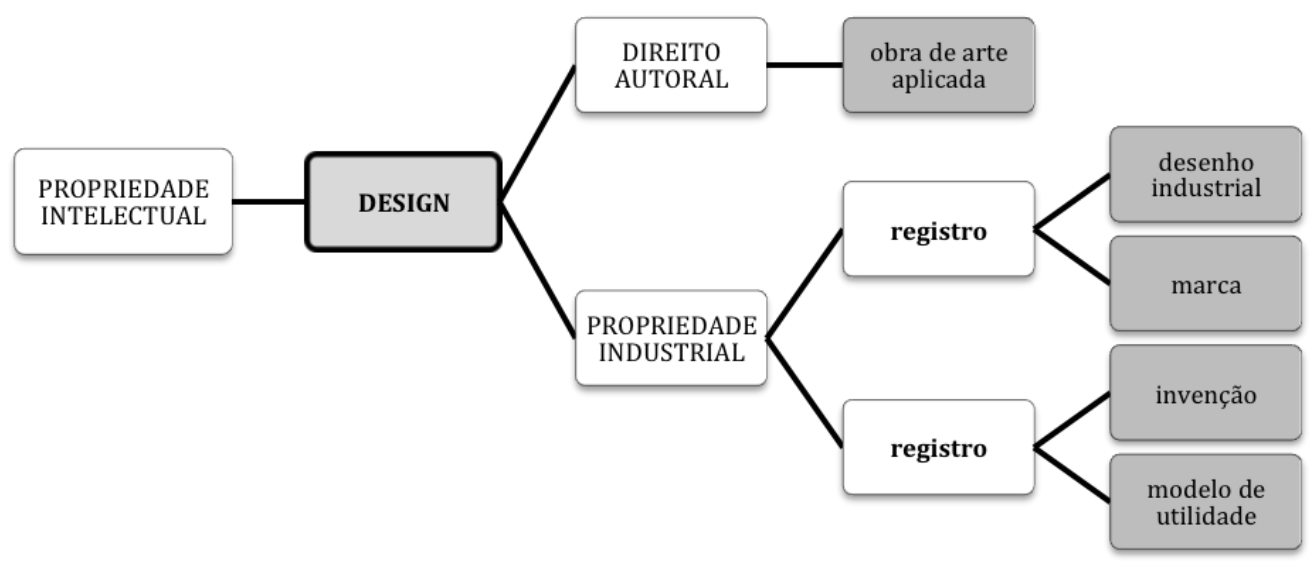

[...] a propriedade intelectual é o grande campo de proteção às criações intelectuais. Especificamente no caso da criação ser o design, esta se divide em duas áreas distintas, que protegem, respectivamente as criações no campo da estética, pelo Direito de Autor e as criações no campo da estética, pela Propriedade Industrial. Através do [...] Direito de Autoral, o design será protegido desde que se apresente sobre a forma de arte aplicada - modalidade da produção artística que se orienta pela criação de objetos, de peças e/ou construções úteis ao homem em sua vida diária. A noção remete a alguns setores da arquitetura, das artes decorativas, do design, das artes gráficas, do mobiliário etc. e traz oposição em relação às belas-artes. Assim, quando um objeto de design tiver forte característica artística, porém esta seja em função da sua utilidade para o homem, caberá a proteção do Direito Autoral. [...] pode-se notar que temos a proteção do design também pelo instituto da Propriedade Industrial. Se de um lado tínhamos a proteção das criações estéticas, deste temos a proteção legal aplicada às criações de ordem técnica, lembrando que a tecnologia, no caso da proteção vista pelos olhos do design, não pode ser fator excludente da estética do objeto. Sendo assim, há quatro formas de se proteger o design: através do registro de marca - é sinal distintivo e visualmente perceptível que confere a seu titular o uso exclusivo, em seu ramo de atividade, para que possa se distinguir o produto ou serviço de outro idêntico ou afim, e de desenho industrial - forma plástica ornamental de um objeto ou conjunto ornamental de linhas e cores que possa ter sua aplicação em um produto, que propicie resultado novo e original na configuração externa e que possa ter sua fabricação industrializada; e através da patente de invenção - nome dado ao bem tecnológico - podendo ser um produto ou serviço - que atenda as características de novidade, atividade inventiva e aplicação industrial, e de modelo de utilidade - objeto de uso prático, ou parte deste, apto para aplicação industrial que apresente nova disposição ou forma, que envolva ato inventivo e, cujo resultado seja uma melhoria funcional em seu uso ou em sua fabricação. Independentemente da proteção ser dada por registro ou por patente, certo é que em ambos os casos o Direito ampara e garante ao autor e/ou titular a exclusividade de uso do bem (MARTINS, 2009, p. 57). 
Com o fim do período da proteção patrimonial da propriedade intelectual, o objeto de proteção cai em domínio público e seu uso se torna livre, conforme previsto nos artigos 41 e 45 da Lei n. 9.610/98, segundo os quais:

Art. 41. Os direitos patrimoniais do autor perduram por setenta anos contados de $1^{\circ}$ de janeiro do ano subsequente ao de seu falecimento, obedecida a ordem sucessória da lei civil.

Art. 45. Além das obras em relação às quais decorreu o prazo de proteção aos direitos patrimoniais, pertencem ao domínio público:

I - as de autores falecidos que não tenham deixado sucessores;

II - as de autor desconhecido, ressalvada a proteção legal aos conhecimentos étnicos e tradicionais (BRASIL, 1998).

De acordo com o prof. José de Oliveira Ascensão (ASCENSÃO, 1997, p. 353) apud (LINKE, 2015, p. 239), o “domínio público em relação à obra não representa nenhum domínio ou propriedade, mas simplesmente uma liberdade ao público", ou seja, a partir do momento que se finda a proteção patrimonial da obra mediante o direito autoral ou industrial, seu uso é livre, pois não há mais um titular exclusivo - o titular da obra caída em domínio público é a própria coletividade.

\title{
4.1 DIREITOS AUTORAIS
}

A Constituição da República dispõe em seu art. 5, inciso XXVII que "aos autores pertence o direito exclusivo de utilização, publicação ou reprodução de suas obras, transmissível aos herdeiros pelo tempo que a lei fixar". E a Lei no 9.610, de 1998 regula os direitos autorais no Brasil (LDA). Relativamente à matéria de direitos autorais tratada pelo legislador constituinte, Cardoso e Carreira (2013) explicam:

\begin{abstract}
a produção intelectual do homem deve ser estimulada e para isso é preciso protegela, pois o progresso das ciências e das artes depende, incondicionalmente, do labor criativo do homem. Para tal proteção, o legislador, não apenas a inclui na Carta Magna, mas the atribui à condição de cláusula pétrea. Portanto, o aspecto constitucional do direito autoral alcança todo o ordenamento jurídico (CARDOSO; CARREIRA, 2013, p. 94).
\end{abstract}

O direito autoral protege as obras do espírito, isto é, todas as criações de forma feitas por uma pessoa humana, seja qual for o gênero, a forma de expressão, o mérito ou o destino. O fundamento legal dos requisitos da proteção por direitos autorais são artigos $7^{\circ}$ e $8^{\circ}$ da LDA, nos quais estão arroladas, de modo exemplificativo, tudo o que a lei considera ou não 
como criações de espírito. No Brasil, assim como na França, o registro da obra é facultativo, ${ }^{5}$ mas sua existência facilita a comprovação em caso de eventual litígio.

Para Motta, (2013, p. 61), saber, então quando determinado conteúdo torna-se apto a ser protegido, torna-se imprescindível para compreender o que leva a sociedade outorgar a uma determinada pessoa exclusividade sobre certa forma de expressão. Identificar os contornos da obra intelectual protegida também auxilia na discussão do nível de rigor dos direitos de autor em relação aos direitos fundamentais dos utilizadores, com vistas ao equilíbrio da relação havida entre estes e o titular de direitos autorais.

\begin{abstract}
De um modo geral, as legislações de diversos países protegem o direito autoral tendo como justificativas razões econômicas ou advindas do direito natural, variando apenas a ênfase dada a cada uma dessas linhas. Sob a perspectiva econômica, busca-se garantir aos autores direito a uma compensação financeira e, dessa forma, estimular a criatividade e produção de obras culturais. Já a segunda perspectiva assenta-se no direito natural de uma pessoa ao produto de seu trabalho, raciocínio que se estenderia às expressões intelectuais criativas. Assim, é comum falarmos em funções de recompensa ao autor pela contribuição ao mundo cultural; de reconhecimento à identificação da autoria; de criação de um ambiente produtivo favorável; incentivos à cultura, sem esquecer-se da função econômica, uma vez que numa sociedade capitalista existe inegável interesse na proteção das criações intelectuais, ante o valor que determinados trabalhos representam, especialmente no âmbito da sociedade de informação, onde há busca incessante pelos conteúdos (MOTTA, 2013, p. 62).
\end{abstract}

Vale ressaltar, que a obra protegida não se confunde com a ideia, mas com a forma pela qual uma ideia é expressa, sendo que essa forma tem um caráter individual próprio, revela algo mais que a mera ideia abstrata.

\begin{abstract}
As ideias são marcadas pelo caráter da universalidade, pertencem ao domínio comum da humanidade. O ser humano é naturalmente provido de ideias. Mais do que isso, a ideias forma a base da comunicação, que não pode ser restringida, não pode ser apropriada. [...] Ideia como plano, projeto abstrato, percepção elementar, conhecimento, informação em si, noção, idealização, modelo, padrão, quando é intenção, projetos como tais, esquemas de ação, não são protegidos, apenas eventualmente e possuindo valor estético. Neste sentido, a obra autoral exige caráter estético, tem plástica, sempre adquire determinada forma sensível apta a despertar a crítica do belo e da harmonia. Veja-se que nem todas as criações possuem caráter estético, caso da generalidade dos direitos industriais (MOTTA, 2013, p. 72-73).
\end{abstract}

$\mathrm{Na}$ França, apesar do design de produto corresponder geralmente à categoria de obras de artes aplicadas, protegíveis pelo direito industrial, há vários exemplos de criações

\footnotetext{
${ }^{5}$ Art. 18 LDA: A proteção aos direitos de que trata esta Lei independe de registro.

Art. 17, Lei 5.988/73: Para segurança de seus direitos, o autor da obra intelectual poderá registrá-la, conforme sua natureza, na Biblioteca Nacional, na Escola de Música, na Escola de Belas Artes da Universidade Federal do Rio de Janeiro, no Instituto Nacional do Cinema, ou no Conselho Federal de Engenharia, Arquitetura e Agronomia (grifo nosso).

Art. L. 111-1, Code de la propriété intellectuelle : L'auteur d'une œuvre de l'esprit jouit sur cette œuvre, du seul fait de sa création, d'un droit de propriété incorporelle exclusif et opposable à tous. [...] (grifo nosso)
} 
realizadas no âmbito de móveis e objetos ligados à arte da mesa que cujo design foi protegido pelos direitos autorais. Lá, conforme (BOOTHERSTONE; MANDEL; MASSOT, 2012), o design da cafeteira modelo Chambord, da marca Bodum (Cour d'appel, Paris, 8 março 2000), foi considerado judicialmente protegido pelos direitos autorais, assim como também foi o design concebido para o modelo de sofá Formentera criado pela marca Roche Bobois (Tribunal de Commerce, Paris, 16 outubro 2009).

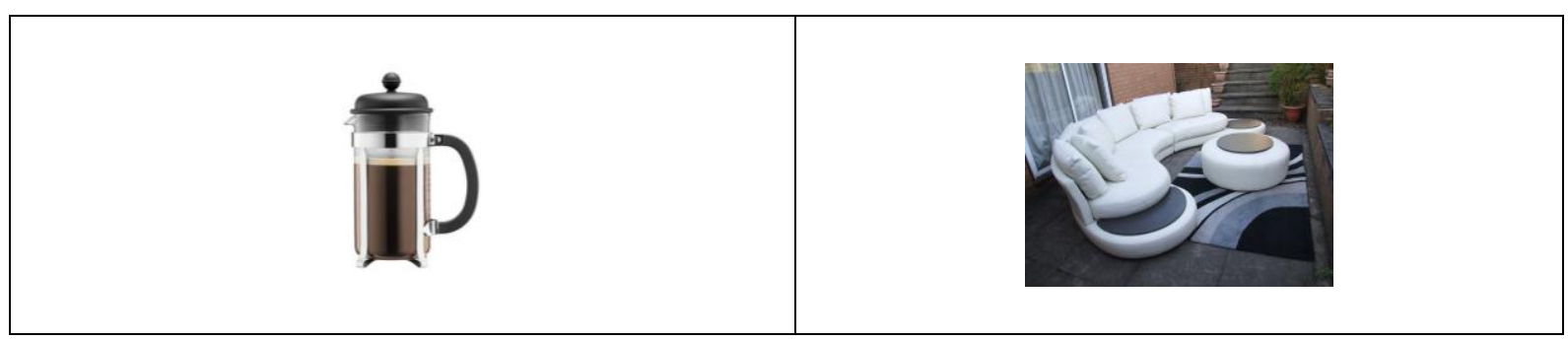

Figura 1 - Fonte: Google imagens

Assim, segundo o direito francês alguns objetos industriais, a cafeteira e o sofá representados na figura acima, podem ser tutelados pela proteção dos direitos autorais.

\subsection{DESENHO INDUSTRIAL}

A proteção dos modelos e desenhos industriais foi instituída, no Brasil, pela primeira vez no Decreto $n^{\circ} 24.507$, de 29 de junho de 1934 e apresentava como requisitos para o a tutela a presença de novidade, originalidade e a exigência de servir de tipo de fabricação industrial.

Embora o país possuísse, a partir da década de 30, a proteção legal para configuração ornamental de um objeto e para um padrão ornamental de linhas e cores para aplicação em um objeto industrializado, os objetos criados por desenhistas industriais brasileiros recebiam, em sua maioria, apenas a proteção de sua funcionalidade por meio das patentes de invenção e de modelo de utilidade. Esse entendimento de que o objeto oriundo da atividade de desenho industrial se refere ao melhor funcionamento do objeto é o entendimento clássico e parcialmente correto, pois a aparência externa do objeto, ou melhor, o embelezamento do objeto ficava sem proteção devido ao desconhecimento de outro tipo de proteção que não a artística e as relativas à melhoria funcional do objeto (GUIMARÃES, 2010, p. 36).

A partir da promulgação da lei $n^{\circ}$ 9.279/96, Lei de Propriedade Industrial (LPI), em vigor, os modelos e desenhos industriais deixaram de ser patentes e se fundiram em uma única natureza de proteção, a do registro de desenho industrial. A LPI assim dispõe:

Art. 95. Considera-se desenho industrial a forma plástica ornamental de um objeto ou o conjunto ornamental de linhas e cores que possa ser aplicado a um produto, proporcionando resultado visual novo e original na sua configuração externa e que possa servir de tipo de fabricação industrial. 
Art. 96. O desenho industrial é considerado novo quando não compreendido no estado da técnica. [...]

Art. 97. O desenho industrial é considerado original quando dele resulte uma configuração visual distintiva, em relação a outros objetos anteriores. [...] (BRASIL, 1996).

Logo, para ser protegido como desenho industrial o objeto deve possuir um grau de distinção em relação a outros, que será analisado de forma visual e comparativa.

Embora o conceito de design tenha uma abordagem ampla, que, em geral, envolve a integração da forma e da função de um objeto, o entendimento da lei no que se refere ao registro de desenho industrial limita o escopo da proteção ao aspecto ornamental. Assim, não são protegidos pelo registro de desenho industrial funcionalidades, vantagens práticas e tipos de materiais ou processo de fabricação.

De acordo com a LPI, o registro de desenho industrial protege a forma que define um objeto e o diferencia dos demais (aspecto tridimensional) e também os padrões gráficos compostos por linhas e cores que, quando aplicados a uma superfície ou a um objeto, tornam possível a sua diferenciação em relação aos similares (aspecto bidimensional).

Os aspectos de design não contemplados pelo registo de desenho industrial, na maioria das vezes, podem ser protegidos por outros recursos de proteção como as patentes de invenção, as patentes de modelo de utilidade, as marcas e o direito autoral.

Para definir Desenho Industrial considera-se oportuno citar (CUNHA, 2003, p.15) apud (SOUZA, 2015, p. 90):

\footnotetext{
Desenho industrial é uma atividade criativa cujo objetivo é determinar as propriedades formais dos objetos produzidos industrialmente. Por propriedades formais não se deve entender apenas características exteriores mas, sobretudo, as relações estruturais e funcionais que fazem de um objeto (ou de um sistema de objetos) uma unidade coerente, tanto do ponto de vista do produtor como do consumidor. O design industrial abrange todos os aspectos do ambiente humano condicionado pela produção industrial.
}

Em seu estudo, SOUZA (2015), afirmou que deve-se evitar tratar as expressões "desenho industrial" e "design industrial" como sinônimos ou equivalentes. Pois, de acordo com ela não há uma tradução exata do termo inglês 'design' para o português, uma tradução aproximada seria projeto, tornando o design algo mais amplo que o conceito de desenho industrial. Design seria a interseção entre a técnica (função prática), o aspecto (função estética) e a arte (função simbólica).

A lei é clara, o registro de DI protege o aspecto visual perceptível de um produto, seja ele em 3 dimensões ou em 2 dimensões. Não protege o design, que é algo muito mais amplo do que apenas o efeito perceptível pelo sentido da visão [...] (GAIARSA apud SOUZA, 2015, p. 91). 
Encontram-se listados no quadro abaixo as diferenças entre Design, Desenho Industrial (com maiúsculas), design, desenho industrial (com minúsculas) e objeto de design segundo (SOUZA, 2015):

\begin{tabular}{|l|l|}
\hline Design e Desenho Industrial & domínio do saber, curso ou disciplina \\
\hline Design & projeto \\
\hline desenho industrial (abreviado como DI) & Modalidade de proteção conferida pela LPI \\
\hline objeto de design & $\begin{array}{l}\text { Produto passível de proteção como desenho } \\
\text { industrial (DI) }\end{array}$ \\
\hline
\end{tabular}

A título de exemplificação do uso dos últimos conceitos apresentados, está ilustrado na figura abaixo uma 'configuração aplicada em caixa para relógio de pulso', objeto de design, passível de proteção por desenho industrial e o correspondente desenho industrial tal como registrado perante o INPI:

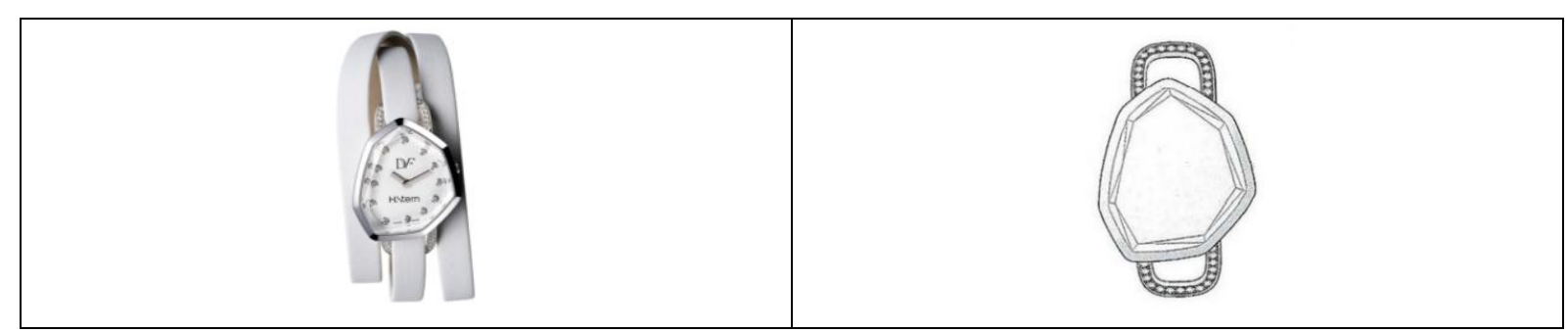

Figura 2 - Relógio Sutra Dvf H. Stern

(a) Imagem do relógio objeto de design do autor/artista Rogério Ferreira Maia para a empresa H. Stern Comércio e Indústria S/A. (b) Registro DI BR 302012 001215-5 Fonte: Google imagens e INPI

Após o deferimento do pedido da proteção do desenho industrial, esta será em todo território nacional e garantirá ao titular o direito de exploração exclusive pelo prazo inicial de 10 anos contados da data do depósito do pedido, podendo este prazo ser prorrogado por mais três períodos sucessivos de 5 anos cada (art. 108, LPI).

Sobre a natureza do desenho industrial, na pratica ele possui as mesmas prerrogativas do privilégio de invenção de impedir que terceiros, sem autorização, produzam, usem, comercializem, coloquem à venda ou importem objeto de desenho industrial registrado (art. 109, LPI). O que se busca é garantir ao titular do registro a prerrogativa de fabricar, de industrializar ou licenciar o seu produto sem que terceiros usufruam de sua criação ou investimento, seu o seu consentimento.

\subsection{DUPLA PROTEÇÃO}


A Convenção de Berna, prevê, caso a legislação e a natureza do objeto permitam, este poderá ser protegido através do desenho industrial e também pelo direito autoral. Nesse caso a proteção é cumulativa. O Decreto $n^{0} 75.699 / 75$ que promulgou a Convenção assim dispõe:

Art. 2.7) Os países da União, reservam-se a faculdade de determinar, nas legislações nacionais, o âmbito de aplicação das leis referentes às obras de arte aplicada e aos desenhos e modelos industriais, assim como as condições de proteção de tais obras, desenhos e modelos, levando em conta as disposições do artigo 7.4) da presente Convenção. Para as obras protegidas exclusivamente como desenhos e modelos no país de origem não pode ser reclamada, nos outros países unionistas, senão a proteção especial concedida aos desenhos e modelos nesses países; entretanto, se tal proteção especial não é concedida nesse país, estas obras serão protegidas como obras artísticas (BRASIL, 1975).

A acumulação de proteção significa que após a expiração do prazo de proteção do desenho industrial que pode chegar a no máximo 25 anos, é possível que o criador do objeto continue gozando da proteção pelo direito autoral. Segundo a Organização Mundial da Propriedade Intelectual (OMPI) o sistema de acumulação é relativamente comum em países europeus. Porém a maioria dos países adota o sistema de coexistência de proteção, no qual o criador pode eleger entre a tutela dos desenhos industriais e a tutela dos direitos autorais.

Em pedido de decisão prejudicial apresentado pelo Supremo Tribunal de Justiça de Portugal, a respeito da dupla proteção de peças de vestuário, assim decidiu o Tribunal Europeu:

Por um lado, o caráter utilitário e funcional dos objetos de artes aplicadas e a sua vocação para serem produzidos industrialmente em massa permitem duvidar da sua aptidão para serem protegidos pelo direito de autor e da conformidade dessa proteção com os seus fundamentos axiológicos (a relação pessoal entre o autor e a sua obra) e com os seus objetivos (a remuneração do esforço intelectual criativo). A proteção dos desenhos e modelos pelo direito de autor comporta, nomeadamente, dois tipos de riscos: a inflação da proteção pelo direito de autor e o entrave à livre concorrência económica. Por essa razão, numerosas ordens jurídicas desenvolveram dispositivos destinados a reservar a proteção pelo direito de autor aos desenhos e modelos que apresentem elevado valor artístico. Pode citar- se a doutrina da «scindibilità», em direito italiano, a «Stufentheorie», em direito alemão, ou a limitação da duração da proteção para os objetos produzidos à escala industrial, no direito do Reino Unido.

Por outro lado, alguns objetos de artes aplicadas têm indiscutivelmente um elevado grau de originalidade. Basta pensar nos estilos desenvolvidos neste domínio, como a Art déco ou a Bauhaus. O mesmo se diga do setor de atividade em causa no presente processo, ou seja, o vestuário: as peças da alta costura são tanto — se não mais obras de arte como vestuário. Por conseguinte, não se justifica excluir a priori os objetos de artes aplicadas da proteção pelo direito de autor, pelo simples facto de terem caráter (também) funcional. Por outro lado, outras categorias de obras, cuja proteção pelo direito de autor não suscita dúvidas, podem também ter funções utilitárias, sem deixarem de ser criações intelectuais originais. É o caso de certas obras literárias, fotográficas e até musicais.

Assim, a opção feita pelo legislador da União, no espírito da teoria da unidade da 
arte desenvolvida na doutrina jurídica francesa, da cumulação da proteção dos objetos de artes aplicadas por um regime sui generis e pelo direito de autor não parece desprovida de pertinência. É, porém, necessário assegurar a autonomia e a realização dos objetivos respetivos de cada regime de proteção.

Com efeito, uma proteção sui generis dos desenhos e modelos, como a prevista pelo Regulamento n. ${ }^{\circ}$ 6/2002, adequa- se à especificidade desses objetos de proteção, isto é, objetos utilitários correntes e produzidos em massa que, no entanto, também podem ter algumas características estéticas originais dignas de proteção. Esta proteção tem uma duração suficiente para permitir rentabilizar o investimento que é constituído pela elaboração do desenho ou modelo, sem, contudo, entravar excessivamente a concorrência. [...] (TJUE. Processo C-683/17. Conclusões do advogado geral Maciej Szpunar apresentadas em 2 de maio de 2019. Cofemel Sociedade de vestuário SA contra G-Star Raw CV) (grifo nosso).

Sobre a dupla proteção na propriedade intelectual, assevera Sofia Kilmar (2014):

A doutrina favorável à cumulação de regimes tem lastro na escola francesa,
especialmente nos casos de conflito entre direito de autor e desenho industrial, com
base na "Théorie de l'unité de l'art" de Eugène Pouillet. Segundo esse doutrinador
francês, cuja "Teoria da Unidade da Arte" foi depois incorporada pela lei daquele
país, o fato de uma obra de arte ter aplicação industrial não a descaracteriza
enquanto criação artística e assim, portanto, ela continua merecedora de tutela
autoral (KILMAR, 2014, p. 14).

No entanto, para Patrícia Porto (2015), os efeitos da dupla proteção podem danosos à sociedade pois podem mitigar e limitar o domínio público; conceder eventual extensão indevida de diretos exclusivos sobre bens em detrimento dos interesses sociais; do direito à livre concorrência e da exaustão de direitos de propriedade intelectual; além de desestimular a criação de mais ativos intelectuais devido ao alto custo para a obtenção de direitos que já deveriam estar em domínio público; e até acabar com a efetividade de políticas públicas na área.

No Brasil, as legislações são silentes sobre casos de tangência entre direitos de propriedade intelectual (art. 98, LPI e art. $8^{\circ}$, VII, LDA), o que abre margem à discussão de eventual abuso de direito, vez que se poderia optar por um direito de propriedade intelectual cujo regime conceda maior prazo e âmbito de proteção. A questão da possibilidade ou não da sobreposição de direitos autorais com a proteção do desenho industrial até o fim deste estudo não foi tratada pelos tribunais brasileiros.

\section{CONCLUSÃO}

A proposta deste estudo foi discutir o descompasso entre os conceitos jurídico e contemporâneo de design, bem como elaborar o enquadramento jurídico da proteção dos objetos de design pelos direitos autorais e pelo desenho industrial. 
Como restou demonstrado design e arte não devem ser considerados sinônimos, pois a arte está ligada puramente a forma e o design é a forma associada à função. Ademais, a concepção de que o desenho industrial é apenas fútil e que merece a proteção por conta de uma combinação estética de linhas e cores é uma visão um tanto quanto ultrapassada da dimensão do conceito de design contemporâneo. Assim, hoje, quando se fala em design, falase de forma mais função.

O pensamento do designer está sempre baseado em uma necessidade, em uma vontade, em um desejo humano. Dessa maneira, existem concepções filosóficas ou de pensamentos baseados no design thinking, ou seja, no pensamento do design, que pressupõe, a necessidade, a vontade e um desejo humano, a partir do qual constrói-se uma solução que une a forma e a função.

Todavia, a legislação ainda está muito vinculada ao caráter fútil e não ao caráter útil do desenho industrial. Segundo a lei, o desenho industrial é uma alteração introduzida no objeto que não amplia sua utilidade, mas apenas lhe atribui um aspecto diferente. No design, não há atividade inventiva, mas apenas a mudança da natureza estética do objeto.

Apesar disso, na prática, há mudança estética e também funcional. Há, por tudo isso, a necessidade urgente de readequação da legislação de direitos autorais e desenho industrial à realidade contemporânea do design.

O conceito de design abrange inúmeras formas e funções de produtos ou serviços que afetam o ambiente de forma positiva. O emprego do design, seja estético ou mental é relevante tanto para as empresas quanto para os consumidores em busca de atingir suas necessidades práticas e emocionais. A valorização da forma emocional, do produto personalizado, oferece ao designer a capacidade de criar objetos em colaboração com o usuário final. Ao adaptar-se aos desejos do consumidor, o design torna-se evolutivo e mais acessível ao público.

Inerente a todas as pessoas, a criação intelectual acontece em nossa sociedade das mais variadas formas, possíveis e imagináveis. Criar, modificar ou aperfeiçoar, e até mesmo copiar um objeto, é característica da evolução do ser humano que busca facilitar a vida de forma agradável. Portanto, será através da propriedade intelectual que o uso do design por terceiros não autorizados será limitado, buscando-se proteger os diretos exclusivos como forma adequada de compensar os responsáveis pelo esforço intelectual de criação e pelo acréscimo que trazem ao mundo cultural. 


\section{REFERÊNCIAS}

ABSTRACT: THE ART OF DESIGN, primeira temporada. Criação de Scott Dadich. Série original Netflix. Produção de RadicalMedia e Tremolo Productions, 2017. 8 episódios (42-48 min), son., col. Série exibida pela Netflix. Acesso em: 2 jan. 2019.

BERCHON, Mathilde. L'impression 3D. 2.ed. Paris: Eyrolles, 2014. 213 p.

BRASIL. Constituição da República Federativa do Brasil de 1988. Disponível em: http://www.planalto.gov.br/ccivil_03/Constituicao/Constituicao.htm Acesso em: $10 \mathrm{dez}$. 2018.

Decreto no 24.507, de 29 de junho de 1934. Disponível em:

http://www2.camara.leg.br/legin/fed/decret/1930-1939/decreto-24507-29-junho-1934498477-publicacaooriginal-1-pe.html Acesso em: 17 dez. 2018.

Decreto $n^{0}$ 75.699, de 6 de março de 1975. Disponível em:

http://www.planalto.gov.br/ccivil_03/decreto/1970-1979/d75699.htm Acesso em: 17 jul. 2019.

Lei 5.988, de 14 de dezembro de 1973. Disponível em:

http://www.planalto.gov.br/ccivil_03/leis/L5988.htm Acesso em: 10 ago. 2019.

Lei 9.279, de 14 de maio de 1996. Disponível em:

http://www.planalto.gov.br/ccivil_03/Leis/L9279.htm Acesso em: 10 dez. 2018.

Lei 9.610, de 19 de fevereiro de 1998. Disponível em:

http://www.planalto.gov.br/ccivil 03/LEIS/L9610.htm Acesso em: 19 dez. 2018.

BOOTHERSTONE, Tamara; MANDEL, Isabelle Marcus; MASSOT, Pierre. Le droit du design. 1 ed. Paris: Dunod, 2012. 281 p.

BROWN, Tim. Design thinking. Set. 2008. Harvard Business Review, América Latina. Disponível em: https://emprendedoresupa.files.wordpress.com/2010/08/p02_brown-designthinking.pdf Acesso em: 14 jan. 2019.

CARDOSO, Marcia Sadi Haron; CARREIRA, Grace Laine Pincerato. A constitucionalidade do direito autoral e a lei 9.610/1998 no ordenamento jurídico brasileiro. In: Anais do VI Congresso de Direito de Autor e Interesse Público. Florianópolis: GEDAI/UFSC, 2012. p. 79-95.

FERREIRA, Aurélio Buarque de Holanda. Novo Aurélio Século XXI: o dicionário da língua portuguesa. $3^{\mathrm{a}}$ Ed. Rio de Janeiro: Nova Fronteira, 1999. p. 2128

FRANÇA. Code de la propriété intellectuelle, Version consolidée au 1 juin 2019. Disponível em:

Revista de Direito, Arte e Literatura | e-ISSN: 2525-9911 | Belém | v. 5 | n. 2 | p. 78 - 98 | Jul/Dez. 2019. 
https://www.legifrance.gouv.fr/affichCode.do?cidTexte=LEGITEXT000006069414\&dateTex te=20190716 Acesso em: 16 jul. 2019.

GABRICH, Frederico de Andrade. Design thinking e direito. In: GABRICH, Frederico de Andrade. (Org.). Inovação no Direito. Belo Horizonte: Universidade Fumec - FCH, 2012, p. 311-348.

GRAU-KUNTZ, Karin. A propriedade intelectual e a proteção das composições de peças de vestuário. In: WACHOWICZ, Marcos. (Coord.). Estudos de Direito da Propriedade Intelectual. 1. ed. Curitiba: Gedai / UFPR, 2015. p. 105-115.

\section{GUIMARÃES, Susana Maria Serrão. Proteção Legal do Desenho Industrial:} entendimentos, conflitos e implicações dos requisitos de novidade e de originalidade. 2010. 153f. Dissertação (Mestrado Profissional em Propriedade Intelectual e Inovação) - Academia de Propriedade Intelectual, Inovação e Desenvolvimento, Coordenação de Programas de PósGraduação e Pesquisa, Instituto Nacional de Propriedade Industrial - INPI, Rio de Janeiro, 2010. Disponível em: http://www.inpi.gov.br/academia/biblioteca/dissertacoes Acesso em: 17 dez. 2018.

HOUAISS, Antônio; VILLAR, Mauro de Salles. Dicionário Houaiss da língua portuguesa. Rio de Janeiro: Objetiva, 2009, $1^{\text {a }}$ reimpressão, com alterações. p. 1986

KILMAR, Sofia Gavião. A dupla proteção em propriedade intelectual face ao abuso de direito. Revista Eletrônica do IBPI, v. I, p. 7, 2014. Disponível em: https://ibpieuropa.org/book/concurso-cultural-aspi-revista-eletronica-do-ibpi-edicao-especial Acesso em: 20 jul. 2019.

KOLKO, Jon. O design thinking atinge a maturidade. 2015. Harvard Business Review Brasil. Disponível em: https://hbrbr.uol.com.br/o-design-thinking-atinge-maturidade/ Acesso em: 14 jan. 2019.

LILLA, Paulo Eduardo. A proteção da propriedade intelectual e seus limites: uma abordagem de law and economics In: TIMM, Luciano Benetti; BRAGA, Rodrigo Bernardes. (Org.). Propriedade Intelectual. 1. ed. Belo Horizonte: Arraes, 2011. p. 123-177.

LINKE, Sarah Helena. A teoria do contributo mínimo criativo e o domínio público em direito de autor: o caso do Google Art Project. In: WACHOWICZ, Marcos.. (Org.). Direito Autoral \& Marco Civil da Internet. 1 ed. Curitiba: Gedai Publicações/UFPR, 2015, p. 237-250.

MARTINS, Renata Gontijo Sant'anna Silva. Proteção Legal ao Design: o caso do Centro eData da Escola de Design da Universidade do Estado de Minas Gerais. 2009. $161 \mathrm{f}$.

Dissertação (Mestrado Profissional em Propriedade Intelectual e Inovação) - Academia de Propriedade Intelectual, Inovação e Desenvolvimento, Coordenação de Programas de PósGraduação e Pesquisa, Instituto Nacional de Propriedade Industrial - INPI, Rio de Janeiro, 2009. Disponível em: http://www.inpi.gov.br/academia/biblioteca/dissertacoes Acesso em: 17 dez. 2018. 
MOTTA, Fernando Previdi. Reflexões sobre os requisitos jurídicos da obra intelectual protegida pelo direito de autor. In: Anais do VI Congresso de Direito de Autor e Interesse Público. Florianópolis: GEDAI/UFSC, 2013. p. 57-78.

ORGANIZAÇÃO MUNDIAL DA PROPRIEDADE INTELECTUAL [OMPI]. Curso Geral de Propriedade Intelectual - DL BR 101. Brasil: INPI, 2015. Módulo 6 - Desenho Industrial.

PENIDO, Patrícia Neves. O registro de desenho industrial no Brasil e no exterior como ferramenta de proteção legal à reprodutibilidade no design de joias. 2016. 186f.

Dissertação (Mestrado Profissional em Propriedade Intelectual e Inovação) - Academia de Propriedade Intelectual, Inovação e Desenvolvimento, Coordenação de Programas de PósGraduação e Pesquisa, Instituto Nacional de Propriedade Industrial - INPI, Rio de Janeiro, 2016. Disponível em: http://www.inpi.gov.br/academia/biblioteca/dissertacoes Acesso em: 17 dez. 2018.

PORTO, Patrícia Carvalho da Rocha. Os efeitos da cumulação de direitos de propriedade intelectual - Direitos autorais x Marcas. In: WACHOWICZ, M. (Org.). Estudos de direito da propriedade intelectual. Curitiba: GEDAI/UFPR, 2015. p. 199-231.

SOUZA, Deborah Portilho Marques de. A propriedade intelectual na indústria da moda: formas de proteção e modalidades de infração. Jan. 2015. 330f. Dissertação (Mestrado Profissional em Propriedade Intelectual e Inovação) - Academia de Propriedade Intelectual, Inovação e Desenvolvimento, Coordenação de Programas de Pós-Graduação e Pesquisa, Instituto Nacional de Propriedade Industrial - INPI, Rio de Janeiro, 2015. Disponível em: http://www.inpi.gov.br/academia/biblioteca/dissertacoes Acesso em: 17 dez. 2018.

TRIBUNAL DE JUSTIÇA DA UNIÃo EUROPEIA. Processo C-683/17. Reenvio prejudicial, direito de autor e direitos conexos, proteção jurídica dos desenhos e modelos, direito de reprodução, vestuário. Recorrente: Cofemel - Sociedade de Vestuário SA Recorrido: G-Star Raw CV. Conclusões do advogado-geral Maciej Szpunar. Luxemburgo, 2 de mai. 2019. Disponível em:

http://curia.europa.eu/juris/document/document.jsf?text=\%2522unit $\% 25 \mathrm{C} 3 \% 25 \mathrm{~A} 9 \% 2 \mathrm{Bde} \% 2$ B1\%2527art\%2522\&docid=213597\&pageIndex=0\&doclang=PT\&mode=req\&dir=\&occ=first \&part=1\&cid=3802964\#ctx1 Acesso em: 23 jul. 2019. 